\title{
Circular citizens research
}

\author{
Nineta Hrastelj Majcen ${ }^{1}$
}

Received: 31 August 2016/Accepted: 16 October 2016/Published online: 9 March 2017

(C) Springer-Verlag Berlin Heidelberg 2016

"Science needs citizens, citizens need science," is a slogan often heard nowadays. It aims at involving citizens in various initiatives related to science and bringing science closer to all. Various ways are proposed on how to put this in practice. Each shall be carefully examined for its potential pitfalls before being implemented. In this editorial, one of the essential aspects is pointed out in this endeavor, i.e. importance of knowledge of systems supporting research, their implementation, outcomes their feedback needed for further research. Briefly presenting the entire landscape - from a research idea to its implementation, at national and at European level — was also the aim of a special session at the EUROANALYSIS conference in Bordeaux in 2015, at which the invitation for this special issue was received.

Which systems and processes are therefore relevant when it comes to interaction of environmental research with the nonresearch communities? Even though not all research in environmental field is directly linked to legislation and/or standardization, both of them are essential to researchers and vice versa. Looking from researchers' point of view, are we doing enough to make ourselves familiar with how to get most up to date research outcomes properly into legislation and standardization, so that we do not end up with, e.g. being requested to measure a certain parameter which we cannot (yet) measure or other scientifically impossible requirements, for which we are also lacking standardized procedures, which help making measurements globally comparable? We have to bear in mind that once a certain piece of legislation or a standardized

Responsible editor: Philippe Garrigues

Nineta Hrastelj Majcen

nineta@euchems.eu

Brussels, Belgium procedure has been approved, it typically takes some years before it gets changed. Furthermore, do we know when and how to approach those in charge of drafting legislation and standards, knowing that environmental legislation is mostly drafted and approved at the European level? Once (environmental) legislation is approved at the European level, it is implemented at the national level. At implementation point, besides national governments, laboratories and accreditation bodies are put at work.

One can wrongly assume that the story ends here. However, if one thinks carefully, this is obviously not the case. Laboratory results are of course meant to be given to those who requested them (users of results). Users of results are not necessarily knowledgeable about science and can easily misunderstand a laboratory report or any aspect of its professional work. This may be illustrated with a simple example of a citizen who is concerned about quality of tap drinking water and would like to know if it is healthy. Those familiar with (bio)chemistry, legislation, accreditation and laboratory work correctly recognize that such request needs a lot of further communication before it can possibly be taken. Another example is when it comes to a sample being analyzed in two laboratories, one of them reporting "measurand not present", the other "below limit of detection (LOD)" and stating a certain number for LOD. Each of these examples would require a rather lengthy discussion with citizens not knowledgeable in this area to get their correct understanding. There are many other examples that show there is urgent need in bringing basic knowledge on how research-legislationimplementation system works to as wide community as possible. This would reduce misunderstandings and misinterpretations and would give citizens "a map" to find their way in this complex landscape. It is also important to take steps in this direction as soon as possible, as social networks, where anybody can post anything, are taking on a role of opinion makers 
pretty fast. If there is no critical mass of those who have the knowledge and are prepared to share it also on social media and by other ways of e-communication, misinterpretations due to lack of knowledge can easily hinder development.

Furthermore, apart from increasing awareness amongst citizens, creating academic platforms where all the interconnected topics are taught by experts would be a long-term commitment.

At such a platform, the following topics should be thought, besides the core environmental research:

a European legislation process with emphasis on environmental files

b European standardization process illustrated by an example of standardization of analytical (measurement) procedures

c Accreditation process for a laboratory

d Quality (metrology) aspects of measurement (analytical) results

e Communication to citizens/customers/journalists/ politicians

Papers in this special issue cover all the above and by doing so I was trying to visualize this complex multi-circular approach amongst research in several scientific disciplines, standardization, accreditation and communication, which are needed for drafting an appropriate legislation and its proper implementation. Systems which underpin the processes have typically well-defined responsibilities. Still, due to their integrated complexity, citizens might easily consider them a jungle rather than pyramidal organized systems as they actually are. Perhaps, the most correct description of the entire landscape would be "a jungle of pyramids with here and there a horizontal social network, when it comes to communication". In this context, a political science student asked one day, why are we (scientists) talking at conferences to ourselves instead of to the others, non-researchers, who hardly know anything about our fascinating research topics, while they are being of a high relevance for all?

There is much more to challenge, debate and improve, but as a conclusion, just a few more questions:

(i) Is circular citizens research the next step of circular economy?

(ii) While we all enjoy art, is it realistic to expect all will enjoy science?

(iii) While we can make art a hobby, can/shall we make science a hobby?

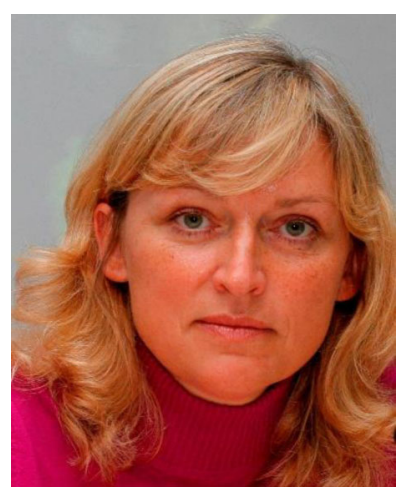

Nineta Hrastelj Majcen Since August 2011, Nineta Hrastelj Majcen is the General Secretary of the European Association for Chemical and Molecular Sciences (EuCheMS). She has a Ph.D. in Analytical Chemistry and Chemometry from the University of Ljubljana, Slovenia. She has worked in national and European organizations, in private and in public domain (University of Ljubljana, Cinkarna Celje, Metrology Institute of the Republic of Slovenia, European Commission), before joining the EuCheMS. She moved from applied research in analytical chemistry and metrology to management positions, being responsible for complex and diversified mostly international projects/programmes/infrastructures, at the cross roads of research, quality of analytical results, standardization, accreditation, legislation, teaching/training and science communication. 